\title{
INDUÇÃO À MACHO-ESTERILIDADE E FORMAÇÃO DE SEMENTES EM GENÓTIPOS DE TRIGO ${ }^{1}$
}

\author{
INDUCTION TO MALE-STERILITY AND CROSS-POLLINATION IN WHEAT
}

\author{
Diego Girardi Pegoraro ${ }^{2}$ José Fernandes Barbosa Neto ${ }^{3}$ Fernanda Schneider $^{2}$ \\ Maria Elena Basilio Sordi ${ }^{2}$ Maria Jane Cruz de Melo Sereno ${ }^{4}$
}

\section{RESUMO}

A variabilidade genética em programas de melhoramento é de extrema importância para o desenvolvimento de novos genótipos. Uma das principais formas de obtenção de variabilidade genética é através da recombinação genética em plantas oriundas do cruzamento de genótipos contrastantes. Em trigo, a obtenção de híbridos é trabalhosa, devido à forma natural e predominante de reprodução, por autofecundação. A indução da macho-esterilidade pode ser uma alternativa para a obtenção de sementes híbridas. O presente trabalho teve como objetivos avaliar a eficiência do gametocida ácido 2cloroetilfosfanico (Ethrel) na indução à macho-esterilidade em trigo, estimar a frequência de polinização cruzada em genótipos de trigo cultivados a campo e determinar o efeito do produto na obtenção de sementes híbridas a campo. O produto foi aplicado em cinco variedades de trigo em três dosagens diferentes, no estádio de pré-emborrachamento, sendo que a ariedade BR 43 (mútica) foi empregada como testadora para verificar a frequência de cruzamentos. Os caracteres avaliados foram: porcentagem de pólen viável, número de grãos produzidos nas espigas ensacadas sem polinização, porcentagem de polinização dirigida e porcentagem de polinização natural. Os resultados indicaram que o produto Ethrel foi eficiente para a indução da macho-esterilidade em todas as variedades testadas: entretanto, ocorreram também prejuízos para o desenvolvimento da parte feminina, evidenciados pela redução do número de sementes produzidas em parcelas tratadas com o gametocida. As doses de 10 e 20 elha causaram acentuada esterilidade de pólen; por outro lado, não foi verificado um incremento na produção de sementes híbridas. Assim sendo, é necessário ajustar a técnica de aplicação do Ethrel para a produção de híbridos em trigo.

Palavras-chave: gametocida, trigo, polinização cruzada

\section{SUMMARY}

The genetic variability is importam for lhe development of new genotypes in breeding programs. This variability is obtained through genetic recombination in plants originated from crosses involving contrating genotypes. However artificial cresses in wheat is a difficult task because of its selfpolinization. The induction of male-sterility may be na altemative for the production of hybrid seeds. The present work had the following objectives: evaluate the efficiency of the gametocide 2-chloroethilphosphonic (Ethrel) in the induction of maleterility in wheat, estimate the frequency of crosspoilination in wheat genotypes cultivated in the field, and verify the effect of Ethrel in the production of wheat hybrid seeds in the field. The product was appiied in five wheat varieties in three different doses in the pre-booting development stage, and the variety $B R$ 43 was used as tester to verify the frequency of crossing. The evaluated traits were: percentage of viable pollen, number of grains produced in protected ears, percentage of artificial and natural cross-poilination. The results indicated that the product Ethrel was efficient in the induction of male-sterility in ali tested genotypes; however, the ovules were aiso affected, evidenced by the reduction in the number of seeds produced in piots treated with the gametocide. The doses of $10 \mathrm{fl}$ a and $20 \mathrm{fl}$ a caused accentuated pollen sterility; on the other hand, na increment in the production of hybrid seeds was not observed. As a consequence, it is necessary to adjust the technique of appiication of Ethrel for the production of hybrid seeds in wheat.

Keys words: gametocide, wheat, cross-poilination.

\section{INTRODUÇÃO}

A variabilidade genética em um programa de melhoramento é um aspecto de extrema importância para o sucesso no desenvolvimento de novos genótipos. Uma das formas principais de obtenção de variabilidade genética é através da recombinaçao de plantas híbridas

${ }^{1}$ Contribuição do departamento de Plantas de Lavoura, faculdade de Agronomia, Universidade federal do Rio Grande do Sul.

${ }^{2}$ Estudante de graduação da Faculdade de Agronomia, Universidade Federal do Rio Grande do Sul (UFRGS), Bolsista CNPq.

${ }^{3}$ Engenheiro Agrônomo, PhD., Professor do Departamento de Plantas de Lavoura, Faculdade de Agronomia da UFRGS, C.P. 776, Porto Alegre - RS. E-mail: jfbn@pro.via-rs.com.br. Autor para correspondência.

${ }^{4}$ Biólogo, Doutor, Professor do Departamento de Plantas de Lavoura, Faculdade de Agronomia, UFRGS 
provenientes do cruzamento de genótipos contrastantes. Em programas de melhoramento genético de trigo, os métodos de desenvolvimento de novos genótipos estão baseados, principalmente, na seleção em populações segregantes obtidas através da hibridação artificial entre duas ou mais linhagens endogâmicas.

O trigo, por ser uma espécie de autofecundação predominante, apresenta algumas dificuldades para a obtenção de plantas híbridas. A emasculação é uma operação que consome tempo e cuidado, limitando os melhoristas a escolherem criteriosamente os cruzamentos a serem realizados a cada ano. Da mesma forma, um pequeno número de sementes híbridas é produzido por espiga cruzada, mesmo com o sucesso na emasculação e na polinização manual. Como consequência, o emprego de métodos de melhoramento que requerem grande número de cruzamentos não é uma alternativa viável para o trigo. Entre estes métodos, a seleção recorrente merece destaque como técnica capaz de elevar a frequência de genes superiores em uma população, incrementando a eficiência na seleção de novas variedades para os agricultores (ALLARD, 1960).

A utilização da macho-esterilidade poderá ser uma alternativa para facilitar a produção de sementes híbridas de trigo. A macho-esterilidade em trigo pode ser obtida geneticamente, por genes nucleares ou pela interação entre genes nucleares e citoplasmáticos (ALLARD, 1960). A exploração destes mecanismos genéticos para evitar a autofecundação implicaria uma série de procedimentos adicionais para o melhorista, como a necessidade de selecionar e manter linhas machoestéreis ou de transferir genes de macho-esterilidade para genótipos com valor económico (VERNA e KUMAR, 1978; SAGE, 1976), requerendo um grande esforço e organização dentro dos programas de melhoramento. Outra forma de obter a machoesterilidade em trigo é com o emprego de produtos químicos, denominados gametocidas, os quais apresentam vantagens como rapidez e facilidade na indução à macho-esterilidade. BARBOSA NETO $\boldsymbol{e t}$ al. (1987) indicaram o uso do gametocida Ethrel para a indução de macho-esterilidade em trigo; sendo a dose e a época de aplicação fatores fundamentais para a eficiência do produto.

Vários produtos químicos têm sido testados para induzir a macho-esterilidade em trigo (PORTER e WIESE, 1961). O Ethrel, produto regulador do crescimento em plantas, parece atuar através da liberação de etileno no interior da planta quando hidrolisado (WILDE, 1971). Segundo LIEBERMAN (1979), o etileno é um importante componente nos processos de regulação hormonal, como o crescimento e a senescência vegetal.
Por outro lado, para possibilitar a utilização de gametocidas em programas de melhoramento de trigo, é importante estimar a frequência de polinização cruzada natural em condições de campo, assim como, determinar o efeito do produto na parte feminina das flores. Informações a este respeito são inexistentes para a cultura do trigo no Sul do Brasil. O presente trabalho teve como objetivos avaliar a eficiência do gametocida ácido 2-cloroetilfosfônico (Ethrel) na indução à macho-esterilidade em trigo, estimar a frequência de polinização cruzada em genótipos de trigo cultivados em condições naturais e determinar o efeito do produto na obtenção de sementes híbridas a campo.

\section{MATERIAL E MÉTODOS}

O experimento foi conduzido na Estação Experimental Agronómica da UFRGS, situada no município de Eldorado do Sul - RS, durante o ano de 1996, sendo utilizadas cinco variedades aristadas de trigo (Embrapal6, BR32, BR23, CEP24 e E7414). A variedade BR43 (mútica) foi empregada como testadora para verificar a produção de sementes híbridas. O delineamento experimental foi o de blocos casualizados com três repetições. As parcelas foram compostas por quatro linhas de três metros, espaçadas de $0,3 \mathrm{~m}$. Uma linha da variedade testadora foi semeada nos bordos dos blocos e entre cada parcela (Figura 1).

O Ethrel foi aplicado em três diferentes dosagens de ingrediente ativo $(0,10$ e 20 $/$ ha) no estádio de desenvolvimento da planta denominado pré-emborrachamento, segundo escala proposta por ZADOKS et al. (1974). A determinação do estádio de desenvolvimento foi realizada com base na parcela inteira, sendo o pré-emborrachamento caracterizado quando $50 \%$ das plantas da parcela apresentavam dois centímetros da bainha da folha bandeira exposta (BARBOSA NETO et al., 1987). A solução contendo o ingrediente ativo do ácido 2cloroetilfosfônico foi aspergida com o auxílio de um

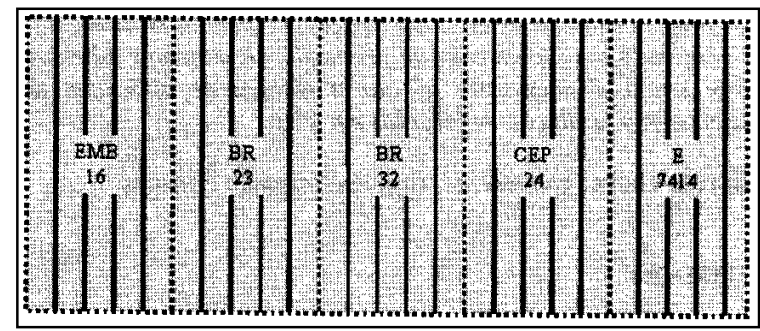

Figura 1 - Esquema gráfico do arranjamento de parcelas no campo experimental, onde linhas cheias correspondem às variedades testadas e as linhas pontilhadas à variedade testadora. 
aplicador manual com volume de $100 \mathrm{~m} \ell /$ parcela. As linhas com a variedade testadora não foram aspergidas.

Para estimar a porcentagem de esterilidade de pólen induzida pelo ácido 2cloroetilfosfônico, cinco espigas foram colhidas, ao acaso, em cada parcela experimental, no estádio de florescimento, segundo a escala ZADOKS et al. (1974). O pólen produzido por estas espigas foi analisado microscopicamente, conforme método proposto por LEWIS \& JOHN (1964). Da mesma forma, outras dez espigas foram ensacadas antes da antese com o objetivo de testar a eficiência de emasculação química. Destas dez espigas, cinco foram polinizadas manualmente com a variedade testadora mútica e as cinco espigas restantes, mantidas ensacadas até o final do período de polinização. A contagem do número de grãos produzidos serviu como indicador da frequência de macho-esterilidade induzida pelo Ethrel. Para verificar a frequência de polinização natural entre os genótipos, outras cinco espigas que apresentaram sintomas visuais de macho-esterilidade foram colhidas. As plantas aspergidas com o produto apresentavam diversas injúrias, principalmente folhas amareladas e redução dos entrenós, determinando uma diminuição da estatura e menor emissão de espigas para fora da folha bandeira. Todas as espigas coletadas no experimento foram provenientes do colmo principal das plantas que apresentavam sintomas de macho-esterilidade induzida pelo produto.

A frequência relativa de polinização cruzada foi estimada através de teste de progénie, em que as sementes das espigas ensacadas e polinizadas e das espigas não ensacadas, obtidas a campo, foram semeadas em telado. Foram escolhidas, ao acaso, dez sementes de cada repetição. As plantas que não apresentaram aristas foram consideradas híbridas, provenientes do cruzamento entre a variedade testa-dora mútica e os genótipos aristados, uma vez que a característica mútica é dominante.

Os dados obtidos foram submetidos à análise de variância, segundo o modelo: $Y_{\mathrm{ijk}}=\mu+$ $\tau_{\mathrm{i}}+\delta_{\mathrm{j}}+\beta_{\mathrm{k}}+\varepsilon_{\mathrm{ijk}}$, onde $\mathrm{Y}_{\mathrm{ijk}}=$ variável analisada (porcentagem de pólen viável, frequência de grãos produzidos nas espigas ensacadas não polinizadas, porcentagem de cruzamento artificial e porcentagem de polinização natural), $\mu=$ média geral, $\tau_{\mathrm{i}}=$ efeito de genótipos, $\tau \delta_{\mathrm{j}}=$ efeito de doses de gametocida, $(\tau \delta) \mathrm{ij}=$ interação genótipo $\mathrm{x}$ dose, $\beta_{\mathrm{k}}=$ efeito de bloco e $\varepsilon_{\mathrm{ijk}}=$ erro $\sim \mathrm{N}\left(0, \sigma^{2}\right)$. A análise de regressão foi realizada para a verificação do efeito das diferentes doses de gametocida empregadas através do modelo $Y_{i}=\beta_{0}+\beta_{1} X_{i}+\varepsilon_{i}$ onde $Y_{i}=$ variável analisada (porcentagem de pólen viável, frequência de grãos produzidos nas espigas ensacadas não polinizadas, porcentagem de cruzamento artificial e porcentagem de polinização natural) $\mathrm{X}_{\mathrm{i}}=$ dose do gametocida, $\beta_{0}, \beta_{1}=$ parâmetros e $\varepsilon_{\mathrm{i}}=$ erro $\sim \mathrm{N}\left(0, \sigma^{2}\right)$. Todos as estimativas foram obtidas com o programa SAS.

\section{RESULTADOS E DISCUSSÃO}

Os resultados obtidos indicaram que o ácido 2-cloroetilfosfônico reduziu a porcentagem de pólen viável nos genótipos testados (Figura 2). Na análise dos grãos de pólen foi observado um grande contraste entre a morfologia dos microsporos em plantas tratadas e não tratadas com Ethrel. Os grãos de pólen observados em plantas não tratadas estavam maduros, com cromatina e completamente cheios de amido (Figura 3); por outro lado, os grãos de pólen inviáveis das plantas tratadas, apresentavam pouca coloração, indicando perda ou

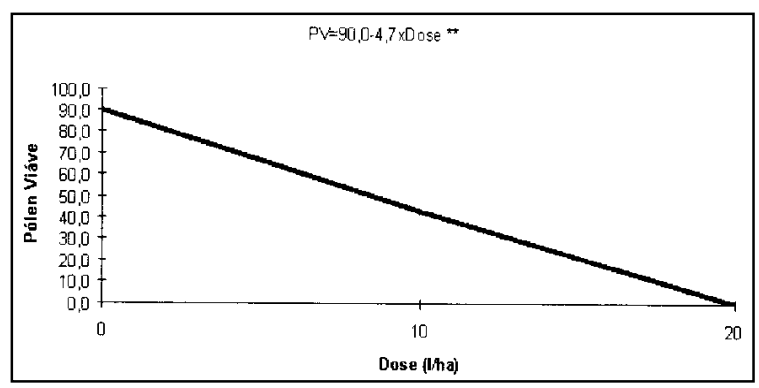

Figura 2 - Análise de regressão para o caráter de pólen viável (PV) para os cinco genótipos de trigo, submetidos a três diferentes dosagens do produto Ethrel.

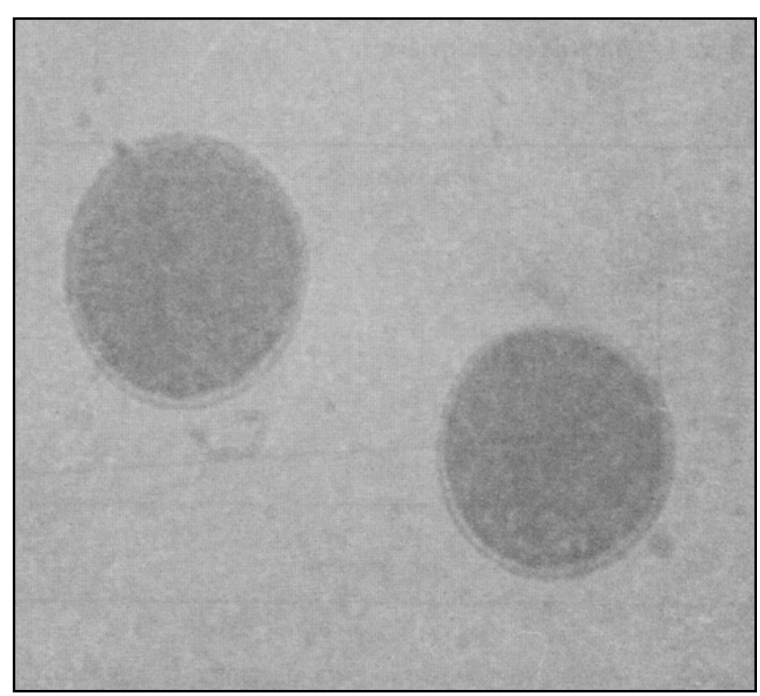

Figura 3 - Grãos de pólen viáveis. 
degradacão de cromatina e baixa acumulação de amido (figura 4). A redução do percentual de pólen viável foi inversamente proporcional à dose utilizada, sendo que todos os genótipos apresentaram resultados similares. A dose $20 \ell$ /ha determinou a menor frequência dos grãos de pólen viáveis. De uma maneira geral, o grão de pólen cessou o desenvolvimento depois da meiose, na primeira divisão mitótica do microgametófito, não havendo acumulação de amido. BARBOSA NETO et $\boldsymbol{a l}$. (1987) e PINTO et al. (1988) obtiveram resultados semelhantes, indicando a eficiência do Ethrel na redução da viabilidade dos grãos de pólen em trigo e aveia, respectivamente.

O número de grãos produzidos nos diferentes genótipos decresceu pela utilização do Ethrel (figura 5). ROWELL e MILLER (1971) também obtiveram uma menor quantidade de grãos com doses elevadas de Ethrel em trigo. Da mesma forma,

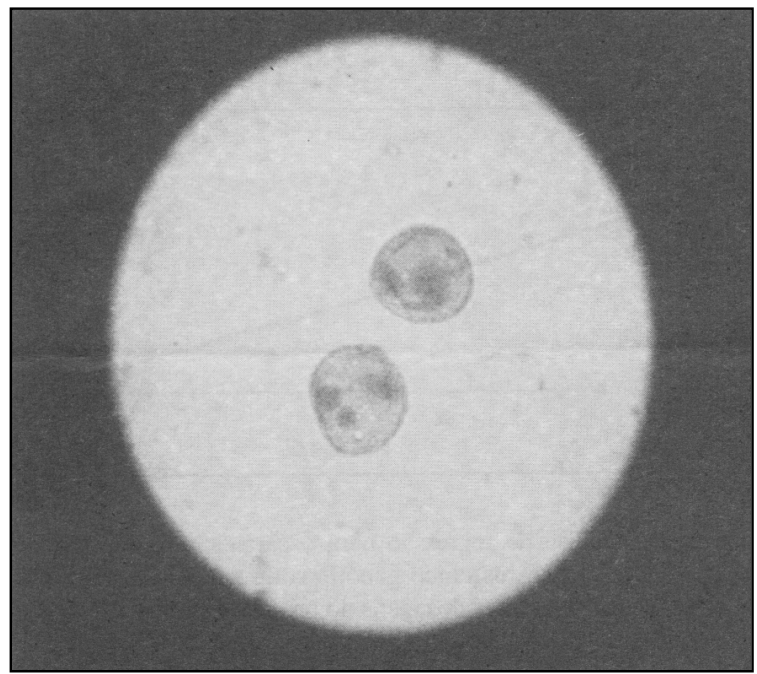

Figura 4 - Grãos de pólen inviáveis.

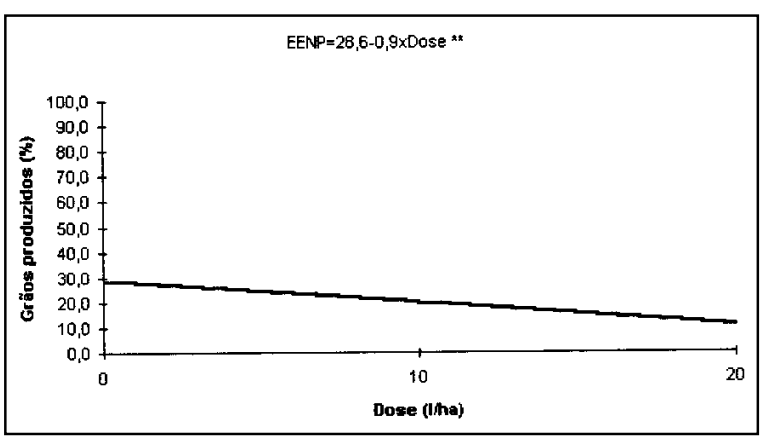

Figura 5 - Análise de regressão para o caráter de número de grãos produzidos (EENP) para os cinco genótipos de trigo, submetidos a três diferentes dosagens do produto Ethrel.
BOSA NETO et al. (1987) e PINTO et al. (1988) obtiveram redução acentuada na produção de grãos nas parcelas testadas com Ethrel. Por outro lado, foi observada a formação de grãos nas espigas ensacadas que não foram polinizadas artificialmente, evidenciando a ocorrência de auto-polinização nas flores das plantas tratadas. A esterilidade parcial do pólen ou a especificidade do momento de aplicação do Ethrel podem auxiliar na explicação destes resultados.

O teste de progénie não revelou um incremento de plantas híbridas (múticas) provenientes das parcelas tratadas com Ethrel e polinizadas artificialmente (figura 6) ou naturalmente (figura 7). A porcentagem de plantas híbridas observada não diferiu de zero em todos os genótipos e dosagens testados, sendo que o comportamento, demonstrado nas figuras 6 e 7, pode ser atribuído a fatores não controlados eficientemente no experimento, como frequência de esterilidade feminina ou baixa dispersão de pólen da variedade testadora, além da época de polinização para a polinização cruzada. Da mesma forma, pode ser sugerido que a técnica empregada para a seleção de plantas afetadas pelo Ethrel não foi adequada. Alternativamente, o Ethrel pode induzir esterilidade da parte feminina das flores, além de machoesterilidade. Assim sendo, a época de aplicação pode ser muito específica e o produto não Ter induzido à esterilidade do pólen das flores das extremidades da espiga, ocorrendo a formação de quantidades suficientes de pólen viável para polinizar toda a espiga.

\section{CONCLUSÕES}

O Ethrel é eficiente para a indução de esterilidade do pólen de trigo, mas afeta o desenvolvimento da parte feminina das flores, evidenciado pela diminuição do número de sementes produzidas nas espigas ensacadas e não polinizadas, o que limita a sua recomendação como gametocida em trigo.

\section{REFERÊNCIAS BIBLIOGRÁFICAS}

ALLARD, R.W. Principies of plant breeding. New York: John Wiley and Sons, 1960.

Ciência Rural, v. 29, n. 2, 1999. 
ISSN 0103-8478

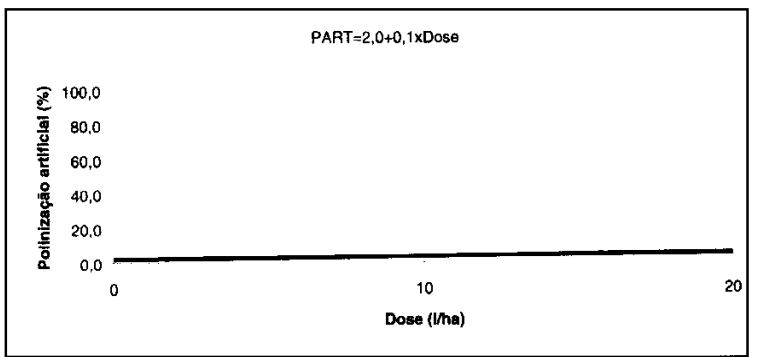

Figura 6 - Análise de regressão para o caráter de polinização artificial (PART) para os cinco genótipos de trigo, submetidos a três diferentes dosagens do produto Ethrel.

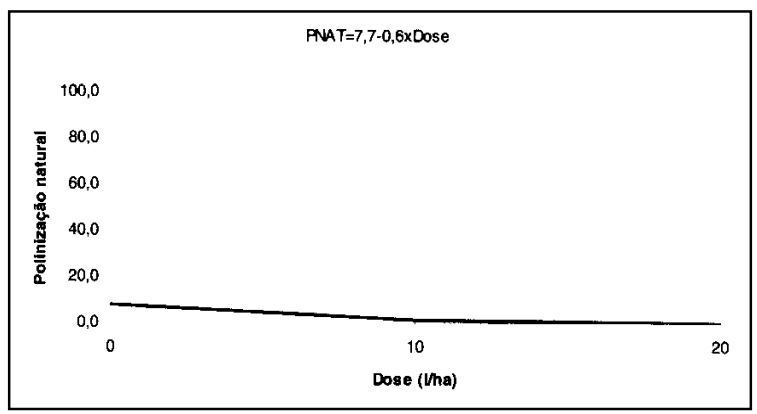

Figura 7 - Análise de regressão para o caráter de polinização natural (PNAT) para os cinco genótipos de trigo, submetidos a três diferentes dosagens do produto Ethrel.

BARBOSA NETO, J.F., CARVALHO, F.I.F., TAVARES, M.J.C.M.S. Esterilidade de pólen em trigo induzida pelo ácido

2-cloroetilfosfônico (Ethrel). Pesq Agrop Brás, v. 22, p. 265274, 1987.

LEWIS, K.R., JOHN, B. The matter of mendelian heredity.London: Churchill, 1964.

LIEBERMAN, M. Biosyntesis and aetion of ethylene. Ann Ver of Plant Physiol, Stanford, v. 30, p. 533-591, 1979.

PINTO, R.J.B., CARVALHO, F.I.F., TAVARES, M.J.C.M., FEDERIZZI, L.C. Induction of male sterility in oats by foliar aplication of 2-cholroethilphosphonic. Revista Brasileira de Genética, Ribeirão Preto, v. 11, p. 369-378, 1988.

PORTER, K.B., WIESE, A.F. Evaluation of certain chemicals as selective gametocides for wheat. Crop Sei, Madison, v. 1, p. 381-382, 1961

ROWELL, P.L., MILLER, D.G. Induction of male-sterility in wheat with 2-cholroethilphosphonic acid (Ethrel). Crop Sei, v. 11, p.629-631, 1971

SAGE, G.C.M. Nucleo-cytosplamatic relationships in wheat. Adv In Agron, v. 28, p. 267-300, 1976.

SÃS Institute. SÃS user guide. Statistics. SÃS Inst, Cary, NC,
1988.

VERNA, M.M., KUMAR, J. Ethrel; a male gametocide that can replace the male-sterility genes in barley. Euphityca. Wageningen, v. 27, p. 865-868, 1978.

WILDE, R.C. Practical aplications of 2-chloroethylphosphonic acidin an agricultural production. Hort Sei, St. Joseph, v. 6, p. $364-370,1971$.

ZADOKS, J.C., CHANG, T.T., KONZAC, C.F. A decimal code for the growth stages of cereais. Weed Rés, Oxford, v. 14, p. 415-421, 1974. 